\title{
Dissolution Profile of Ibuprofen Solid Dispersion Prepared with Cellulosic Polymers and Sugar by Fusion Method
}

\author{
Nadia Saffoon ${ }^{1}$, Yeakuty Marzan Jhanker ${ }^{2}$ and ${ }^{*}$ Naz Hasan Huda ${ }^{3}$ \\ ${ }^{1}$ Product Executive, Marketing Strategy Department, Ziska Pharmaceuticals Ltd., Dhaka-1000, Bangladesh. \\ ${ }^{2}$ Department of Pharmacy, The University of Asia Pacific, Dhaka-1209, Bangladesh. \\ ${ }^{3}$ Department of Pharmacy, Stamford University Bangladesh, 51, Siddeswari Road, Dhaka-1217, Bangladesh.
}

Original Research Article

\begin{abstract}
The purpose of this study was to prepare and characterize solid dispersions of the NSAID Ibuprofen with HPMC, HPC, icing sugar, dextrose, mannitol and lactose with the intention of improving its dissolution properties. The solid dispersions were prepared by the fusion method. Evaluation of the properties of the dispersions was performed using dissolution studies. The results obtained showed that the rate of dissolution of Ibuprofen was considerably improved when formulated in solid dispersions with HPMC and HPC. Solid dispersions with icing sugar, dextrose, mannitol and lactose showed drug retarding capability which may trigger more research in the intension of exploiting this feature to prepare sustained release dosage form.
\end{abstract}

Key words: Ibuprofen, Solid dispersion, Fusion method, Dissolution rate.

\section{INTRODUCTION}

Among all non-steroidal anti-inflammatory drugs (NSAID), Ibuprofen can be wellmentioned for its wide usage in the treatment of mild to moderate pain and fever (Moore, 2003). For any drug to exhibit its prompt pharmacologic action, its serum concentration has to reach optimum level within a short period of time (Buxton, 2006). Thus rapid ibuprofen absorption could be a prerequisite for the quick onset of its action (Rainsford, 2003). Because of its high membrane permeability characteristic, extent of ibuprofen absorption approaches up to $100 \%$ (Martinez et al., 2002). Therefore, dissolution becomes the rate limiting step for absorption and the quick release of

*Corresponding Author
Naz Hasan Huda
Assistant Professor
Department of Pharmacy
Stamford University Bangladesh
51, Siddeswari Road
Dhaka-1217, Bangladesh
E-mail: nazhasan@mail.com
Phone: +88 01199027212

ibuprofen in the gastrointestinal tract following oral administration is desirable (Newa et al., 2008, Levis et al., 2003; Matthias et al., 2005). Enhancing solubility and dissolution rate of poorly water-soluble drugs like ibuprofen is one of the striking areas of research in pharmaceutical field (Dhirendra et al., 2009). To overcome the problems associated with oral absorption and bioavailability issue, various strategies have been utilized including prodrug formation (Murtha and Ando, 1994), complexation (Ghorab and Adeyeye, 2001), microcapsulation (Adeyeye et al., 1994), the use of surfactants, lipids, permeation enhancers, micronization, salt formation, cyclodextrines, nanoparticles, solid dispersions, self emulsifying drug delivery system (Shakhtshneider et al., 1996; Craig, 2002; Gao and Morozowich, 2006; Rane et al., 2007; Tang et al., 2007) etc. However ahead of all, solid dispersion is the most promising method to the scientists due to the ease of preparation, ease of optimization and reproducibility of the manufacturing method 
(Chiou and Reigelman, 1971; Ford, 1986; Law et al., 1991; Leuner and Dressman, 2000).

Many methods like spray drying, coprecipitation, co-evaporation and freeze dying are used for solid dispersion manufacturing; however, costly equipments are required along with complicated procedures. Apart from these techniques, fusion method is a method of choice because it is environmentally friendly, cost effective, represents no stability nor toxicity problems and can be easily scaled up for commercial purpose (Bhandari et al., 2007).

The aim of this study was to prepare different solid dispersions of Ibuprofen by fusion method with two cellulosic polymers, named Hydroxy Propyl Methyl Cellulose (HPMC) \& Hydroxy Propyl Cellulose (HPC) and four sugars, named icing sugar, dextrose, mannitol and lactose. The aim of the study was also to characterize them by dissolution studies to evaluate the effect of these carriers on solubility profile of Ibuprofen.

\section{MATERIALS AND METHODS}

Experimental material: Ibuprofen RS was gift sample from Orobinder, India. HPMC $6 \mathrm{cps}$ and HPC were obtained from Samsung, Korea. Icing sugar, Dextrose Lactose and Mennitol were purchased from BDH. Reagent: Di-sodium hydrogen phosphate and Sodium di-hydrogen phosphate (Merck, Germany); all other ingredients used were of analytical grade. Equipment: USP dissolution tester-Apparatus-II (VEEGO, India); UV Spectrophometer (UV mini1204, SHIMADZU CORP., Koyoto, Japan); Digital $\mathrm{pH}$ meter $(\mathrm{pH} 211$ Microprocessor $\mathrm{pH}$ Meter, HANNA Instruments, Romania); Electronic balance (AY 120, SHIMADZU CORP., Koyoto, Japan); Sieve (Endecott's Test Sieve, Endecotts Limited, England); glass vials, water bath, dessicator etc.

\section{Preparation of the solid dispersion}

Fusion method was used for the preparation of solid dispersions of ibuprofen (Dhirendra et al., 2009; Vasconcelos et al., 2007). Required amount of drug, polymer and sugar is shown in Table 1 and 2. Ibuprofen was taken in a previously washed and cleaned moisture free glass vial and was heated in a water bath at a temperature range of $80^{\circ} \mathrm{C}-90^{\circ} \mathrm{C}$ until a clear solution was obtained. Polymer or Sugar was added to the clear solution and heating was continued till a homogeneous mixture was obtained. Continuous stirring of the drug and polymer was ensured using a glass rod to prevent the separation of the constituents. As homogeneous mixture achieved, the vial was taken out of the water bath. Stirring was continued and solid mass was obtained. The solid mass in the vial was kept in a dessicator. After complete removal of moisture the solidified formulation was crushed in a mortar and pestle, size reduced and sieved through a 150 micron sieve. All glass vials were labeled with care and kept in dessicator. Samples for dissolution studies were taken from the vials.

\section{Preparation of phosphate buffer $\mathrm{pH} 7.2$}

7.34gm di-sodium hydrogen phosphate and $1 \mathrm{gm}$ sodium hydroxide were weighed out and dissolved in small amount of distilled water, volume was adjusted to 1 liter with the same solvent to prepare 1 liter phosphate buffer. The $\mathrm{pH}$ of the buffer solution was adjusted using a $\mathrm{pH}$ meter.

\section{In vitro dissolution Study}

These studies were conducted at $37 \pm 0.5^{\circ} \mathrm{C}$ on an USP specification dissolution rate test type II apparatus (Paddle apparatus) with six sections assembly according to the USP 30 procedure (USP 30 and NF 25, 2007). For in vitro dissolution studies, phosphate buffer $\mathrm{pH} 7.2$ was used as dissolution media. Water-bath temperature was fixed \& confirmed to be $37 \pm 0.5^{\circ} \mathrm{C}$ before starting the experiment. The medium was preheated to $37^{\circ} \mathrm{C}$ and then a quantity of $900 \mathrm{ml}$ was added to each vessel. The apparatus was then assembled and paddle rotation was started and adjusted at $100 \mathrm{rpm}$ and the system was allowed to equilibrate for 15 minutes.

After that the paddle rotation was stopped and fixed amounts of solid dispersion containing $50 \mathrm{mg}$ equivalent ibuprofen from each batch were placed in the vessels. The apparatus was immediately operated at 100rpm. Each vessel, vessel position and corresponding sample result 
Table 1. Different ratios of Ibuprofen with HPMC and HPC.

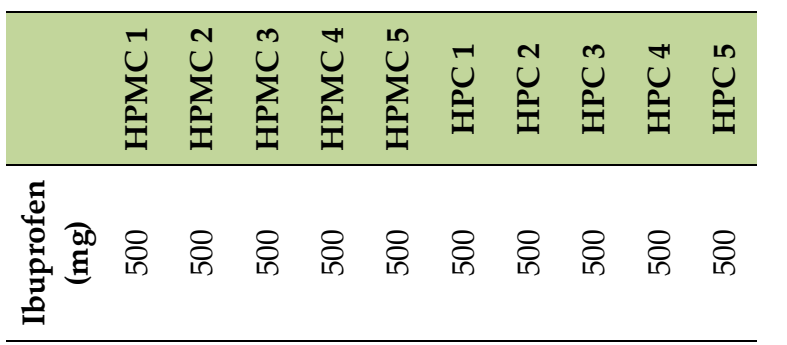

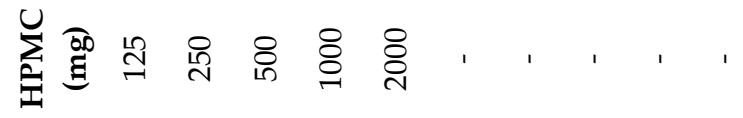

$$
\text { 嵌 }
$$

were assigned the same code. The duration of the experiment was 60 minutes for each set of sample.

$10 \mathrm{ml}$ of sample was withdrawn from the media at pre-determined intervals of 5, 10, 15, 20, 30, 45,60 minutes. Each and every time $10 \mathrm{ml}$ of dissolution sample was compensated by adding $10 \mathrm{ml}$ fresh phosphate buffer. The sample solutions were diluted and analyzed at $221 \mathrm{~nm}$ for ibuprofen by UV spectrophotometer. The amount of drug present in the samples was calculated from calibration curve constructed from the standard solution of USP reference standard test drug.

\section{RESULT AND DISCUSSION}

Effects of cellulosic polymers (HPMC and HPC) on solid dispersion of Ibuprofen are shown in Figure 1 and 2.

\section{Effect of HPMC}

Using HPMC as polymer gave $100 \%$ release of ibuprofen from solid dispersions within 15 minutes when drug to polymer ratio were 1:4 and 1:2. Drug to polymer ratio of 1:1, 2:1 and 4:1 gave $100 \%$ release of drug from the formulations in a time frame of 30 minutes, 45 minutes and 60 minutes respectively.

\section{Effect of HPC}

Data showed that $100 \%$ release of ibuprofen was attained within 15 minutes when ibuprofen to HPC ratio was 1:4 which is significantly faster than compared to ibuprofen-HPC ratio of 1:2 (it took 30 minutes to release ibuprofen by $100 \%$ )and 1:1 (it took 45 minutes to release ibuprofen by $100 \%$ ). $2: 1$ and $4: 1$ ibuprofen to HPC ratio solid dispersions failed to release $100 \%$ drug within 60 minutes and released $99.96 \%$ and $91.16 \%$ of drug, respectively.

Effects of sugars (icing sugar, dextrose, mannitol and lactose) on solid dispersion of Ibuprofen are shown in Figure 3 to 6.

\section{Effect of icing sugar}

Incorporation of icing sugar in the formulation improved release of drug. But no formulation was able to release $100 \%$ ibuprofen within 60 minutes time frame. As the amount of sugar was increased \% release of ibuprofen improved but the increment was insignificant.

\section{Effect of dextrose}

Dextrose based formulations showed improved drug release from the solid dispersions. But even drug to sugar ratio of 1:4 did not give $100 \%$ release of ibuprofen within 60 minutes. Increasing polymer percentage improved drug release rate but in an insignificant way.

\section{Effects of Mannitol}

Mannitol based solid dispersions also failed to release $100 \%$ drug within 60 minutes. When the drug to sugar ratio was $1: 4,90.84 \%$ of drug released from the solid dispersions. At drug to sugar ratio of 4:1 the release within 60 minutes was $74.53 \%$.

\section{Effects of lactose}

Lactose based formulations showed very poor drug release. 4:1, 2:1, 1:1, 1:2 and 4:1 drug to sugar ratio released drug by $64.64 \%, 67.22 \%$, $71.94 \%, 75.37 \%$ and $77.51 \%$ respectively within 60 minutes.

Among HPC and HPMC based solid dispersions of ibuprofen, HPMC based solid dispersions gave faster dissolution profile in comparison to HPC based solid dispersions. At higher 
Table 2. Different ratios of Ibuprofen with icing sugar, dextrose, mannitol and lactose.

\begin{tabular}{|c|c|c|c|c|c|c|c|c|c|c|c|c|c|c|c|c|c|c|c|c|}
\hline & 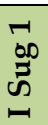 & $\begin{array}{l}N \\
\infty \\
= \\
0\end{array}$ & $\begin{array}{l}m \\
\infty \\
= \\
\text { क }\end{array}$ & $\begin{array}{l}\text { म } \\
00 \\
\text { की }\end{array}$ & $\begin{array}{l}10 \\
\infty 0 \\
\overrightarrow{0} \\
1\end{array}$ & $\begin{array}{l}\vec{x} \\
x \\
\text { II }\end{array}$ & $\begin{array}{l}\underset{x}{x} \\
\text { Ir }\end{array}$ & $\begin{array}{l}\stackrel{m}{x} \\
\stackrel{1}{a}\end{array}$ & $\begin{array}{l}\text { 艾 } \\
\text { II }\end{array}$ & $\begin{array}{l}\text { L } \\
\text { I⿱ } \\
0\end{array}$ & $\stackrel{J}{\exists}$ & $\begin{array}{l}N \\
\text { 当 } \\
\Sigma\end{array}$ & $\stackrel{m}{e}$ & $\stackrel{+}{E}$ & 足 & ư & 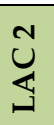 & $\sum_{1}^{\infty}$ & 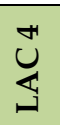 & $\underbrace{10}_{1}$ \\
\hline 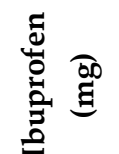 & $\underset{1}{8}$ & \& & $\underset{10}{8}$ & 8 & $\underset{\text { ஜn }}{8}$ & $\underset{10}{8}$ & 8 & 8 & $\underset{10}{8}$ & \& & $\underset{10}{8}$ & $\underset{10}{8}$ & \& & \& & $\underset{10}{8}$ & $\underset{1}{8}$ & $\underset{10}{8}$ & 8 & 8 & $\underset{10}{8}$ \\
\hline
\end{tabular}

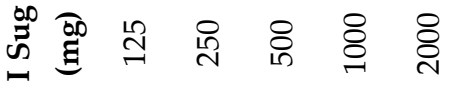

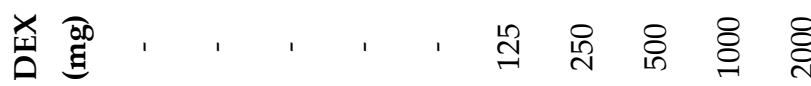

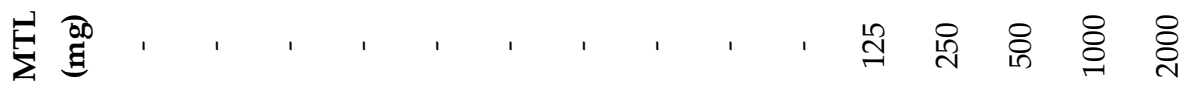

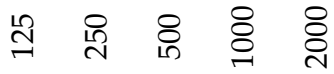

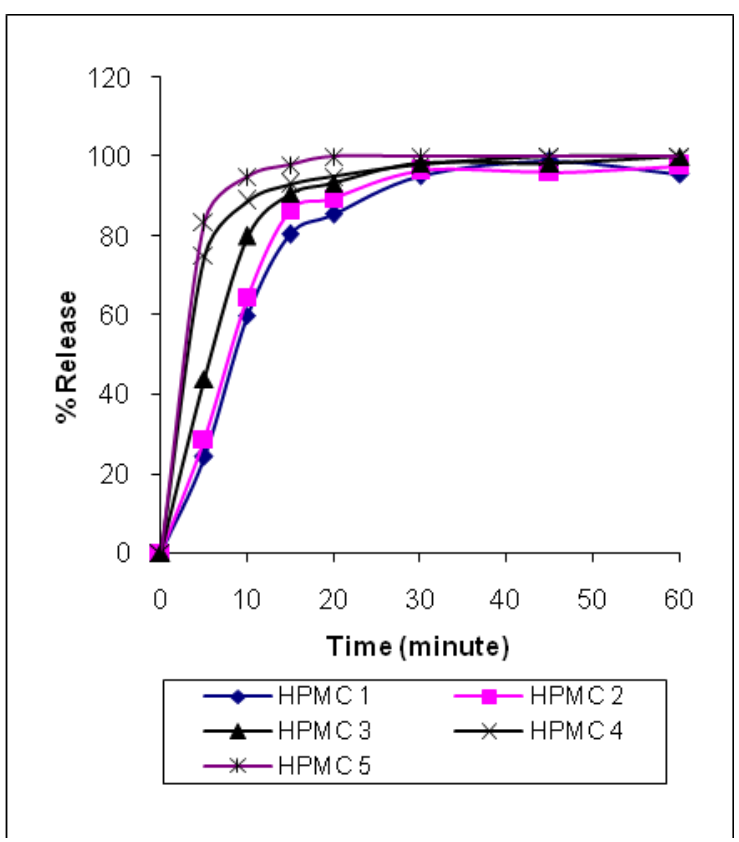

Figure 1. Percent release of ibuprofen from solid dispersions prepared in different polymer ratios of HPMC.

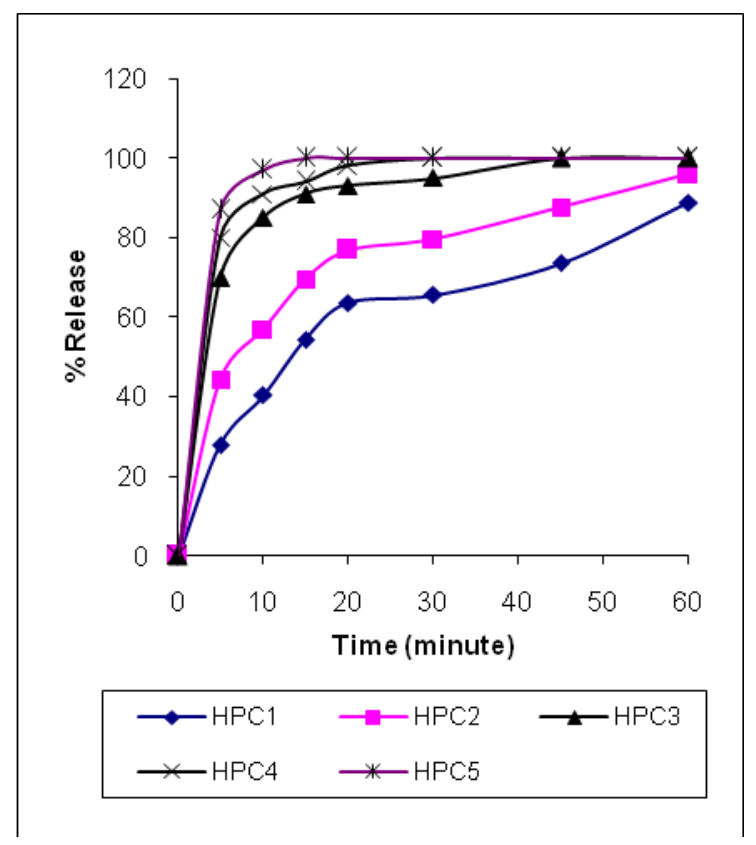

Figure 2. Percent release of ibuprofen from solid dispersions prepared in different polymer ratios of HPC. 


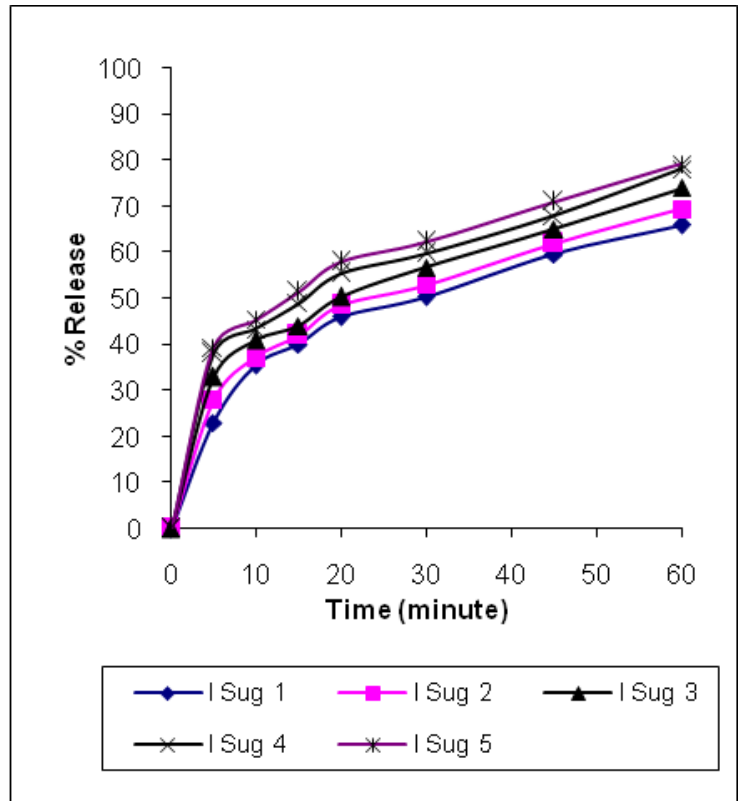

Figure 3. Percent release of ibuprofen from solid dispersions prepared in different polymer ratios of icing sugar.

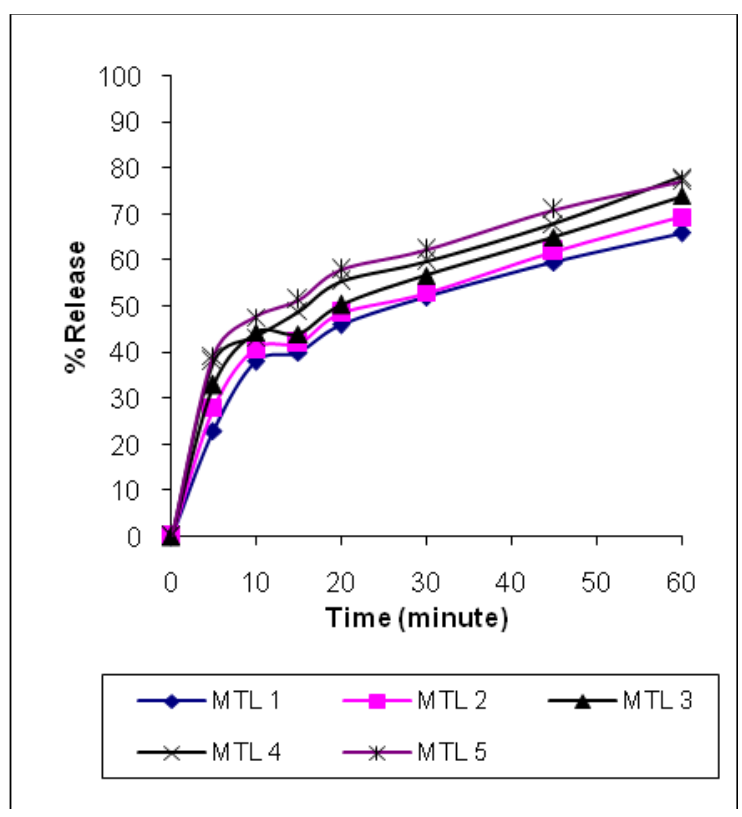

Figure 5. Percent release of ibuprofen from solid dispersions prepared in different polymer ratios of mannitol.

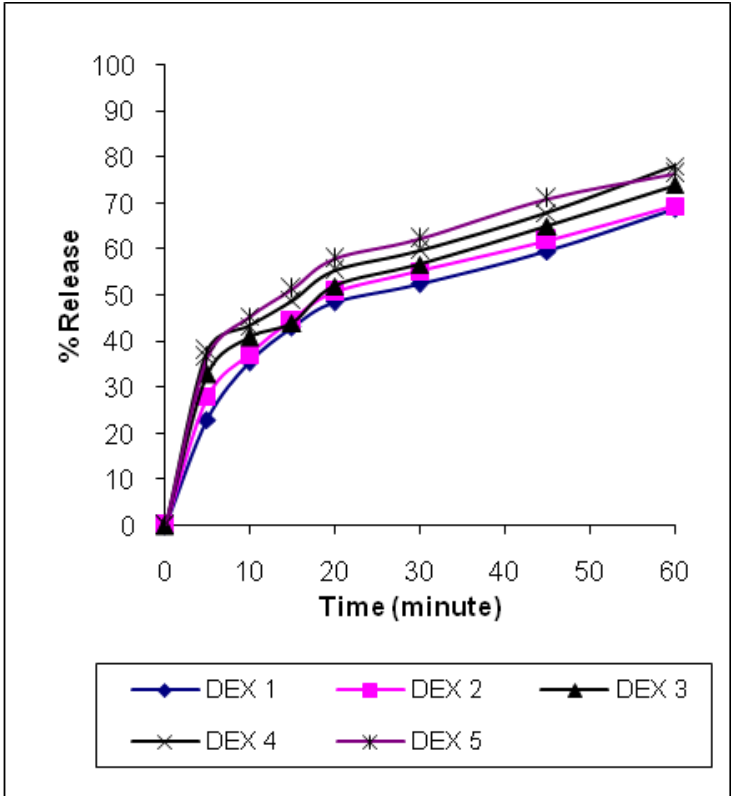

Figure 4. Percent release of ibuprofen from solid dispersions prepared in different polymer ratios of dextrose.

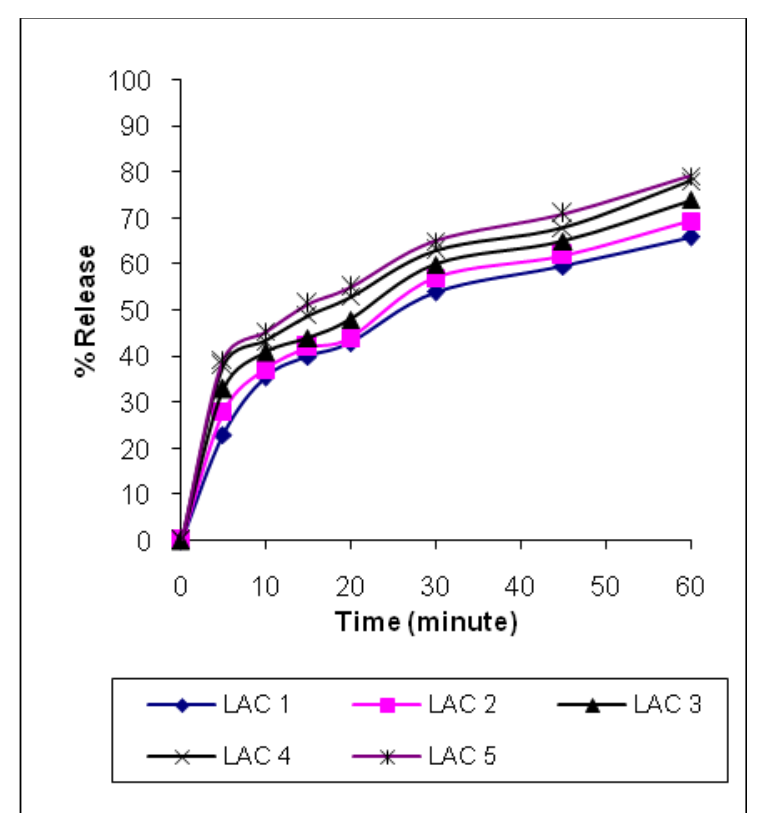

Figure 6. Percent release of ibuprofen from solid dispersions prepared in different polymer ratios of lactose. 
concentration of HPC and HPMC (1:4) the release rate was almost same; $100 \%$ release of drug within 15 minutes. When the polymer percentage was in between $65-80 \%$, both HPC and HPMC showed nearly same dissolution profile.

Whereas, none of the four sugar based solid dispersion formulations was able to release drug by $100 \%$ within 60 minutes dissolution time. Drug release rate of dextrose and icing sugar was similar. Highest drug release was found with solid dispersions prepared using icing sugar $(97.23 \%$ release of ibuprofen within 60 minutes when drug to sugar ratio was 1:4; at the same ratio dextrose based formulations released $96.78 \%$ of drug).

\section{CONCLUSION}

Solid dispersions are of immense importance now-a-days in the development of poorly water soluble drugs in oral solid dosage forms with enhanced dissolution rate and thus improved oral bioavailability (Huda et al., 2010; Uddin et al., 2010). In our experimental protocol we used fusion method to prepare solid dispersions of ibuprofen. Cellulosic polymers (HPMC and HPC) and four sugars (icing sugar, dextrose, mannitol and lactose) were used in the work. It is clear from the data obtained that a higher polymer concentration gave faster drug release. Again, from the discussion it can be concluded that solid dispersion systems have a potential usage as controlled release drug delivery system with careful use of different polymers along with sugars. It will be interesting to observe the outcome of such experiments.

\section{REFERENCES}

Adeyeye CM, Price JC (1994). Development and evaluation of sustained-release ibuprofen-wax microspheres-II. In vitro dissolution studies, Pharm. Res. 11: 575-579.

Bhandari KH, Newa M, Kim JA, Yoo BK, Woo JS, Lyoo WS, Lim HT, Choi HG, Yong CS (2007). Preparation, characterization and evaluation of coenzyme Q10 binary solid dispersions for enhanced solubility and dissolution, Biol. Pharm. Bull. 30: 1171-1176.
Buxton ILO (2006) In - Goodman \& Gilman's - The Pharmacological basis of Therapeutics (2006) 11th Edition, McGraw-Hill Medical Publishing Division, Digital Edition, Chapter 1.

Chiou WL, Reigelman S. (1971). Pharmaceutical applications of solid dispersion systems. J Pharm Sci. 60(9): 1281-1302.

Craig DQM (2002). The mechanisms of drug release from solid dispersions in water-soluble polymers. Int. J. Pharm. 231: 131-144.

Dhirendra K, Lewis S, Udupa N, Atin K (2009). Solid Dispersions: A Review. Pak. J. Pharm. Sci. 22(2): 234246.

Ford JL. (1986) The current status of solid dispersions. Pharm Acta Helv. 61:69-88.

Gao P, Morozowich W (2006). Development of supersaturatable self-emulsifying drug delivery system formulations for improving the oral absorption of poorly soluble drugs. Expert Opin. Drug Deliv. 3(1): 97-110.

Ghorab MK, Adeyeye MC (2001). Enhancement of ibuprofen, dissolution via wet granulation with beta-cyclodextrin. Pharm. Dev. Technol. 6: 305-314.

Huda NH, Saffoon N, Jhanker YM (2010). Dissolution Enhancement of Ibuprofen Solid Dispersion Prepared with Vinyl Polymers by Fusion Method. Stamford Journal of Pharmaceutical Sciences. 3(2): 7-11.

Law SL, Lo WY, Lin FM, Chaing CH (1992). Dissolution and absorption of nifedipine in polyethylene glycol solid dispersion containing phosphatidylcholine. Int. J. Pharm. 84: 161-166.

Leuner C, Dressman J. (2000). Improving drug solubility for oral delivery using solid dispersions. Eur J Pharm Biopharm. 50:47-60.

Levis KA, Lane ME, Corrigan OI (2003). Effect of buffer media composition on the solubility and effective permeability coefficient of ibuprofen. Int. J. Pharm. 6: 49-59.

Martinez MN, Amidon GL (2002). A mechanistic approach to understanding the factors affecting drug absorption: a review of fundamentals. J Clin Pharmacol. 42: 620-643.

Matthias K, Arne R, Stefan S, Dirk T, Chris S, Bernd L, Gunther B (2005). Ibuprofen extrudate, a novel, rapidly dissolving ibuprofen formulation: relative bioavailability compared to ibuprofen lysinate and regular ibuprofen, and food effect on all formulations. J. Clin. Pharmacol. 45: 1055-1066.

Moore N (2003). Forty years of ibuprofen use. Int J Clin Pract Suppl. 135: 28-31.

Murtha JL, Ando HY (1994). Synthesis of the cholesteryl ester prodrugs cholesteryl ibuprofen and 
cholesteryl flufenamate and their formulation into phospholipid microemulsions. J. Pharm. Sci. 83: 1222-1228.

Newa M, Bhandari KH, Kim JA, Yoo BK, Choi HG, Yong CS, Woo JS, Lyoo SK (2008). Preparation and evaluation of fast dissolving ibuprofenpolyethylene glycol 6000 solid dispersions. Drug Delivery. 15:355-364.

Rainsford KD (2003). Discovery, mechanisms of action and safety of ibuprofen. Int J Clin. Pract. Suppl. 135: 3-8.

Rane Y, Mashru R, Sankalia M, Sankalia J (2007). Effect of hydrophilic swellable polymers on dissolution enhancement of carbamazepine solid dispersions studied using response surface methodology. AAPSPharmSciTech. 8(2): Article 27.

Shakhtshneider TP, Vasiltchenko MA, Politov AA, Boldyrev (1996). The mechanochemical preparation of solid disperse systems of ibuprofenpolyethylene glycol. Int. J. Pharm.. 130: 25-32.

Tang J, Sun J, He ZG (2007). Self-emulsifying drug delivery systems: strategy for improving oral delivery of poorly soluble drugs. Current Drug Therapy. 2: 85-93.

Uddin R, Saffoon N, Huda NH, Jhanker YM (2010). Effect of Water Soluble Polymers on Dissolution Enhancement of Ibuprofen Solid Dispersion Prepared by Fusion Method. Stamford Journal of Pharmaceutical Sciences. 3(1): 63-67.

United States Pharmacopeia 30 and National Formulary 25 (2007) The United States Pharmacopeial Convention, CD ROM.

Vasconcelos T, Sarmento B, Costa P (2007). Solid dispersions as strategy to improve oral bioavailability of poor water soluble drugs. Drug Discovery Today 12(23-24): 1068-1075. 